\title{
Problems and Prospects of Interdisciplinarity: The Case of Philosophy of Science
}

\author{
Marie I. Kaiser, Maria Kronfeldner, and Robert Meunier ${ }^{1}$
}

\begin{abstract}
:
In this paper, we discuss some problems and prospects of interdisciplinary encounters by focusing on philosophy of science as a case study. After introducing the case, we give an overview about the various ways in which philosophy of science can be interdisciplinary in Section 2. In Section 3, we name some general problems concerning the possible points of interaction between philosophy of science and the sciences studied. In Section 4 we compare the advantages and risks of interdisciplinarity for individual researchers and institutions. In Section 5, we discuss interdisciplinary PhD programs, in particular concerning two main problems: increased workload and the quality of supervision. In the final Section 6, we look at interdisciplinary careers beyond the $\mathrm{PhD}$.
\end{abstract}

\section{Introduction}

Early-career scholars and scientists who are trained in a specific discipline or field but want to work in an interdisciplinary manner often find themselves caught between a rock and a hard place, facing conflicting demands. While they have to meet the rigorous standards of a career in their home discipline, they are at the same time expected to possess detailed knowledge of the field they want to connect with in an interdisciplinary approach. By pulling in different directions, these two poles can be difficult to bridge.

Philosophy of science is a field that is deeply affected by such a tension. Interdisciplinarily engaged philosophers of science face not just an increased workload, but also institutional conditions that are not always supportive for their projects. For instance, while the need for interdisciplinary research is impressed upon young researchers by their advisers and by the subject matters of their research, universities and funding institutions, by contrast, still follow rather conservative and disciplinary policies when they fill positions or allocate funding.

In March 2013, the interdisciplinarity of philosophy of science and the resulting situation for early career researchers was the subject of a workshop and a panel discussion funded by the Andrea von Braun Foundation. ${ }^{2}$ This paper takes up several of the issues that were controversially disputed at that event and develops them further.

The central goal of this paper is to illuminate the actual situation of interdisciplinary research in philosophy of science: what are its promises, and which institutional and practical conditions constrain or impede interdisciplinarity in practice? Our analysis will focus on the situation in Germany, though the points we make might be applicable more broadly, that is, also to the situation in other countries and to other fields.

We begin in Section 2 with an overview on the various ways in which philosophy of science can be interdisciplinary. Section 3 specifies some of the general conditions that make interdisciplinary engagement in philosophy of science a practical challenge. In Section 4 we explain why for the individual researcher as well as for institutions interdisciplinary engagement is both, promising and risky at the same time. We also point to some specific structural conditions that often impede interdisciplinarity in practice. Sections 5 and 6 continue

\footnotetext{
$1 \quad$ Authors appear in alphabetic order.

The title of the event was: 'Caught between a rock and a hard place': Prospects and problems of careers between philosophy and science. It took place in the context of the first conference of the German Society for Philosophy of Science (Gesellschaft für Wissenschaftsphilosophie) in Hanover, Germany. See http://www.wissphil.de/index.php?site=gwp2013\&subsite=panel (last access August 6, 2013). We want to thank the Andrea von Braun Foundation, as well as the workshop participants and the panelists, who are listed on the above-mentioned page. We also want to thank the colleagues and students who organized the conference in Hannover and made it possible that the event could take place in such a facilitating setting. This article is an extended version of a report on the event that will be published in Briefe zur Interdisziplinarität. For proof-reading of the shorter version we thank Peta Hinton.
} 
these discussions, but with a special focus on problems and prospects in planning a career under these conditions. We address questions such as 'How can early-career philosophers (i.e., PhD students, Section 5, and postdoctoral researchers, Section 6) deal with the conflicting demands they face?' and 'Which job requirements arise from interdisciplinary research?' The Conclusion (Section 7) summarizes our results and provides an outlook.

\section{Different Forms of Interdisciplinarity in Philosophy of Science}

Philosophy of science is a field that can be characterized by different styles: general philosophy of science can be distinguished from the philosophies of the particular sciences; while the former can be synoptic or reflective, the latter can be reflective or embedded. Some of these styles are more prone towards interdisciplinary, some are less so.

Synoptic philosophy of science is interdisciplinary in the sense that it addresses a general scientific problem. It synthesizes knowledge from different disciplines and draws the broadest possible generalizations concerning a problem or approach that is not a genuine philosophical, that is, reflective problem, but rather a problem addressed by the scientists themselves. The focus is on a synoptic, theoretical approach that is applied to many different problems and thus contributes to the disciplines that deal with those problems. For instance, when philosophers develop a generalized version of evolutionary theory in order to test whether it applies to fields outside of evolutionary biology, they address a general scientific problem in a synoptic manner.

Embedded philosophy of science is interdisciplinary in the sense that it addresses methodological or conceptual scientific problems that are rather specific to a discipline, such as the method of genetic analysis or the concepts of function or species in biology, or the concepts of space and time in physics. Philosophers share that respective problem as a common scientific problem and help scientists in solving it.

Reflective philosophy of science is interdisciplinary in the sense that it can have interdisciplinary relations (with various degrees of collaboration) with other reflective disciplines that have sciences as their object of study, such as history, sociology or cognitive studies of science. They typically ask reflective questions that the scientists themselves do not address, for example how the social structure of science is related to claims of objectivity regarding the knowledge produced. We call this kind of interdisciplinarity reflective-level interdisciplinarity. Different reflective disciplines share a common reflective problem (e.g. objectivity of scientific knowledge production) in trying to understand how science works.

Reflective philosophy of science can also - but less obviously than synoptic philosophy of science or embedded philosophies of the particular sciences - enter into collaborative relationships with the respective sciences studied (i.e., into a relation where they share a common problem). This is the case for instance when scientists themselves address a reflective (i.e., a philosophical) problem such as whether their ways to draw causal influences is methodologically appropriate. These are cases of interdisciplinarity with respect to reflective problems.

All of these styles can be purely descriptive (i.e., making factual claims about how science actually works) or normative (i.e., specifying how science should work). The degree of normativity is often inversely related to the degree interdisciplinarity. Normative styles will typically worry not as much about actual scientific practice and knowledge. The more normative an approach, the more it is possible to ignore what actually happens in the sciences. The more it ignores the details of scientific activity, the less interdisciplinary a style is. Frequently, however, even normatively oriented philosophers of science seek to understand how science in fact works and, to be able do so, they interact with scientists. . (For a more elaborated analysis of all these points, see Kaiser, Kronfeldner, and Meunier 2014). ${ }^{3}$

\section{General Impediments for Interdisciplinarity}

Those philosophers who agree on the need to engage with scientific knowledge and practice might still disagree on how to solve two kinds of problems that impede interdisciplinarity in a general manner. There are, first, what we call problems of selectivity of interdisciplinary philosophy of science and, second, problems of inconsistency. Problems of selectivity concern the question, which parts of scientific knowledge or knowledge about scientific practice are of particular importance to developing a certain philosophical approach (and which role this knowledge plays in this process). Problems of inconsistency concern the question what we should do if scientific knowledge or practice conflicts with what philosophers claim.

3 A similar typology of ways in which philosophy can be related to the special sciences is presented in Reydon and Hoyningen-Huene (2011). 
A common strategy to solve the first problem is to focus on paradigmatic (i.e., representative) examples and/or on instances of successful science. Yet, this paradigmatic- or winner-perspective might mischaracterize the actual process of scientific knowledge production. Furthermore, this only postpones the problem because the question then is how to specify the success of science and how to choose between different criteria to identify successful science. Discussions about these criteria are a bona fide normative issue in philosophy of science and there is, after all, no agreement on these criteria among philosophers. Yet, even other disciplines interacting in interdisciplinary ways need a solution for problems of selectivity.

The second problem concerns what to do when there is an inconsistency between two disciplines interacting in an interdisciplinary manner. For instance, if Darwinism provides a challenge in the sense that it entails that there is no human nature in the traditional sense that philosophers hitherto assumed (see Kronfeldner, Roughley and Toepfer 2014, on that example), who has to move in order to create consistency or enable interaction? If there is a "corrective asymmetry," in the sense of Steel's (2004) discussion of relations between disciplines, then just one of the conflicting parties would have to adapt (e.g., philosophy towards the sciences), rather than both adapting to each other. There exists no general solution to this issue, neither regarding sciences interacting among each other, nor regarding the relationships between philosophy of science and sciences.

Problems of selectivity and inconsistency are issues that address general impediments interdisciplinary research has to face since they will occur in philosophy of science as well as in other interdisciplinary fields. They are the kind of problems that gave rise to a separate branch of philosophy: philosophy of interdisciplinarity (see Andersen and Wagenknecht (2013) for an example of this branch and for a more in-depth discussion of general impediments like the two mentioned). To understand interdisciplinarity is itself an issue of philosophy of science.

\section{The Institutional and the Individual Perspective}

Interdisciplinarity and disciplinarity are not in contradiction. Indeed, interdisciplinary research obviously presupposes the existence of disciplines. Nevertheless, the aims of single disciplines and interdisciplinary fields do not necessarily match, and the practices of institutions (universities, funding bodies, policy makers) and the needs of individual researchers are not always in perfect accord.

For institutions the advantage of interdisciplinary research lies in its promise to fulfill societies' demands to understand and handle complex and multifaceted phenomena such as climate change or the production of scientific knowledge, for that matter. Yet, a small department might not be able to hire people with interdisciplinary profiles since they will struggle to have enough people to cover their own discipline in its entirety, which they usually have to do, at least in Germany. Thus in the case of philosophy of science, a structural reason for why more conservative decisions (i.e., decisions against increasing interdisciplinarity) are made at the level of universities and departments may be that philosophy departments are often quite small (we elaborate on this point in Section 5).

Furthermore, a general problem consists in the necessity to foresee the need for interdisciplinary approaches before these have proven to successfully address a problem, especially because a phenomenon might only appear as multifaceted once it has been addressed from various perspectives. It is difficult to predict the outcome of interdisciplinary research and to evaluate the methods and concepts suggested in interdisciplinary proposals, as well as the competences of those who put forward such projects (Hornbostel and Olbrecht 2007, Huutoniemi 2010).

For an individual researcher the advantage of interdisciplinary research is the possibility to generate innovative results, that is, results that are not only new, but of a new type. The dangers lie in having insufficient knowledge in at least some of the involved fields, in needing too much time to produce results, as well as in not fitting institutional schemes. In sum, interdisciplinarity requires the investment of additional resources while from the perspective of individual researchers as well as of institutions it is difficult to determine under which circumstances and to what extent these additional costs are worthwhile.

Interdisciplinarity is thus a risk, and it needs structures that support risk-taking profiles and that provide a robust foothold for such enterprises. Current funding - it seems to us - is often not very robust (and is thus unpredictable in itself) and rather risk-aversive. Finally, more radical changes in perspective and shifts from one discipline to another seem to be impeded because it is almost impossible to achieve funding for a project that involves aspects that have little to do with the applicant's previous research (since for a successful application one would usually need relevant publications in all covered fields). Accordingly, funding and institutional structures should improve in following a principle of robust support and risk promotion. 


\section{Interdisciplinary PhD Programs}

At first glance, the $\mathrm{PhD}$ level seems particularly suited for interdisciplinary research. Before that stage, in their basic training, students might want to specialize in one discipline, and afterward, professors might be committed to the disciplinary identities of the departments in which they are employed (more on interdisciplinarity at later stages in Section 6). PhD researchers, by contrast, are required to perform original research and at the same time enjoy (still) relative independence in their work.

In Germany doctoral level study and research is increasingly organized in structured programs (as opposed to the "individual doctorates" that used to be common in the past) and many of them have an interdisciplinary profile. Such programs harbor chances as well as risks for those who host them as well as for the individual PhD candidates (see Hornbostel 2009).

On the side of the chances for early-career scholars, interdisciplinary PhD programs can function as zones of transition for researchers who wish to change fields, for instance, graduates from the natural sciences who wish to switch to the humanities or the social sciences (in the other direction the boundary seems to be less permeable). They can apply for and contribute to the program with their expertise in their former discipline and accumulate expertise, contacts, and publications necessary for further employments in the new field during the course of the program.

Concerning the risks, there are two major considerations: the extended workload and the quality of supervision. First, interdisciplinary $\mathrm{PhD}$ projects create problems for $\mathrm{PhD}$ candidates in that they produce a double workload. Students are expected to possess detailed knowledge in all fields involved in the interdisciplinary framework, and while they will bring with them expertise in at least one field, they have to acquire much basic knowledge about the other field(s) involved in parallel to their actual thesis-relevant research. This is a difficult task, especially given that in structured $\mathrm{PhD}$ programs in Germany candidates are typically expected to finish their thesis within three years. While studying two subjects is typically well represented in a CV and is, accordingly, acknowledged as a worthwhile reason for an extended period of study, quasi auto-didactic acquisition of knowledge from another discipline or informal exchange (e.g. through lab visits) is usually not documented and a resulting increase in the average time needed to finish an interdisciplinary $\mathrm{PhD}$ project might be evaluated rather negatively by potential future employers. Institutions hosting and fostering interdisciplinary $\mathrm{PhD}$ projects should therefore try to find ways to promote additional interdisciplinary training (e.g., by organizing lab visits or proper internships) and to make it visible (e.g. by awarding certificates).

The management of workload seems to require that the PhD candidate's engagement with the new science be tailored to the needs arising from the individual research project. Interdisciplinary research projects are extremely idiosyncratic because, in the best case, they develop a new intersection between fields. Furthermore, they might change significantly during the time of their development because it might only become clear in the course of the project where such fruitful intersections lie. Somehow in contradiction to this, structured $\mathrm{PhD}$ programs tend to be regulated in many respects, and if they have an interdisciplinary profile they might install rigid schemes of interdisciplinary training and exchange (critics often point out the increasingly school-like character of $\mathrm{PhD}$ programs, in particular with respect to their restructuring in the context of the so-called Bologna-process). Given the different types of interdisciplinary relations that we introduced in Section 2 (see also Kaiser, Kronfeldner, and Meunier 2014), as well as the idiosyncratic and dynamic character of such projects, such rigidity should be avoided. Instead, interdisciplinary programs, while providing opportunities for interdisciplinary training and spaces for various forms of interdisciplinary exchange, should adopt a principle of flexible form and ratio of interdisciplinary engagement for the $\mathrm{PhD}$ candidates.

The second problem concerning risk that arises for early-career researchers, as well as for institutions hosting interdisciplinary programs, is how to find appropriate advisers and collaborators for an interdisciplinary $\mathrm{PhD}$ project. Even if there are advisers from every discipline involved in the interdisciplinary project, it is still possible that none of them has an expertise in the genuinely interdisciplinary aspects of the project, or with interdisciplinary work and its strategies and pitfalls in general. In addition, senior researchers might have limited interest in functioning as advisers or collaborators because they do not see the direct benefit of the work for their own research. A senior scientist, for instance, will have less interest than a senior philosopher in a philosophical analysis of a concept that the scientist uses on a daily basis without any problems, despite the ambiguity in the concept viewed in a broader and philosophical context. With respect to this point, interdisciplinary programs need to provide incentives for senior researchers to engage with interdisciplinary doctoral projects even if they cannot see a direct benefit. To put it differently, interdisciplinary programs in philosophy of science should consciously acknowledge a principle of asymmetry with respect to the benefit of interdisciplinary engagement of $\mathrm{PhD}$ students and their collaborators from different disciplines and act accordingly to compensate the asymmetry.

Supporting and educating young scholars is already a good motivation for engaging in interdisciplinary projects 
as the less benefiting partner. However, such an asymmetry might not be limited to the relation between PhD candidates and supervisors, but might apply to interdisciplinary projects in general. Also in a non-educational interdisciplinary partnership we think that there are good reasons to cooperate for those partners who benefit less with respect to their immediate research interests. For instance, such a cooperation might make accessible additional funding sources, facilitate public outreach activities, and enhance conceptual work or research design.

Our discussion of interdisciplinary $\mathrm{PhD}$ education focused on structured $\mathrm{PhD}$ programs that explicitly aim at facilitating interdisciplinary research. However, there are still many $\mathrm{PhD}$ candidates who do not participate in structured programs. But also for this group the points mentioned might provide useful guidelines for organizing their research, establishing a supportive environment, and effectively ask and argue for the kind of support they need.

\section{Interdisciplinarity Beyond the PhD}

As mentioned in the beginning, one of the major risks for young researchers in pursuing research in an interdisciplinary field is that, although it seems to be the case that interdisciplinarity is called for and promoted on the level of education, and especially on the $\mathrm{PhD}$ level, there are not many permanent positions with an interdisciplinary profile. Hence, researchers with an interdisciplinary career either will do worse in the long run, or they are forced to choose one discipline as their focus. What makes things worse is that the profile of many professorships in Germany is very broad and the opinion that the profile of appropriate candidates must also be broad is still very widespread. Given that interdisciplinarity often comes with a narrowing of focus in the home discipline, this creates a lot of worries among postdoctoral researchers concerning the right extent of interdisciplinarity in their profile.

For institutions such as universities and funding bodies, one problem with permanent interdisciplinary positions can be that - as mentioned in Section 4 - the form and success of interdisciplinary research is difficult to anticipate and evaluate, and fruitful interdisciplinary constellations can change quickly. Therefore, it is difficult to establish interdisciplinary positions with a predetermined content. If, however, thematically open interdisciplinary professorships, for instance, are awarded on the basis of promising proposals, they are still difficult to locate in the standard structures of a typical university, at least in Germany.

Given that the success of interdisciplinary projects is difficult to predict, but nevertheless desirable and worthy of promotion because of the promise of interdisciplinarity to generate synergistic effects between fields of knowledge or even new types of knowledge, results and competences, institutions often seem to follow a pragmatic approach. A common strategy is to rely on existing disciplinary structures, but provide incentives for senior researchers to engage in interdisciplinary projects or collaborations from the vantage point of their clearly defined disciplinary identities. While also supporting interdisciplinary graduate education, the "German Universities Excellence Initiative", for instance, seems to be based on the idea of linking existing disciplines on the level of senior research (Clusters of Excellence), rather than implementing genuinely interdisciplinary positions or departments, although within Clusters of Excellence there seems to emerge a tendency for crossdisciplinary hiring in order to create mediating positions (Sondermann et al. 2008, 91).

In general, young researchers in philosophy of science, who are interested in building a strong interdisciplinary profile should know about and evaluate the problems of and impediments on interdisciplinarity early on, and plan their careers accordingly. One important point to take into account is the national context in which a career is pursued. As mentioned above, in Germany philosophy departments usually expect a broad philosophical knowledge from members of their faculty and interdisciplinary philosophers of science might have to take care to remain able to satisfy that demand. However, specialization within philosophy, which often comes with an interdisciplinary orientation, might be more valued in other academic environments, for instance in US research universities, though certainly not in colleges. Keeping this in mind is particularly relevant when the career development involves switching between different national contexts (as it is usually advised - job offers today usually target candidates with international experience).

Young philosophers developing an interdisciplinary profile should also reflect on their position and understand how they are perceived in order to learn how to argue for and promote their interdisciplinary approach. Especially those researchers pursuing the embedded style of philosophy of science might be confronted with the accusation that what they do is not philosophy, but rather theoretical science. Answering to such claims requires a self-conscious reflection about what philosophy is and can be. To remind ourselves that the separation between the special sciences and philosophy, which both used to be part of „,natural philosophy, " is a modern development and the fact that philosophers working on scientific problems retain their own methodological approaches, e.g. conceptual analysis, might be obvious starting points for constructing convincing arguments for an interdisciplinary outlook in philosophy. Learning how to plan an interdisciplinary career and how to 
represent it to others is an aspect that interdisciplinary Master or $\mathrm{PhD}$ programs can also facilitate.

\section{Conclusion}

Interdisciplinary initiatives often falsely assume that interdisciplinary exchange always is, or should be, equally useful for all sides involved. However, different benefits for the involved disciplines, or one-sided benefits, should be seen as an acceptable outcome of interdisciplinarity (principle of asymmetry with respect to the benefit of interdisciplinary engagement).

A major problem for institutions in implementing interdisciplinarity is to predict where fruitful interdisciplinary fields will emerge and to evaluate proposals and results. The latter is difficult since potential referees are unlikely to have the same interdisciplinary profile as the researchers evaluated. One strategy is to take the principle of robust support and risk promoting seriously. Universities could, for instance, foster interdisciplinary exchange of existing disciplines by creating permanent positions with an emphasis on interdisciplinary collaboration, without setting up interdisciplinary departments. The advantage of this approach to interdisciplinarity is that it exploits the full potential of new interdisciplinary fields or even creates new interdisciplinary connections by supporting new interdisciplinary research personas as they might arise from interdisciplinary $\mathrm{PhD}$ programs, without creating a scheme that is too rigid and thus promotes risk-aversive approaches again.

If early-career researchers adapt to the current overall situation in their career planning by maintaining a home in a traditional discipline, the advantage is that a self-made interdisciplinary network on the basis of institutional incentives for exchange and collaboration from inside a discipline can be more easily adjusted and reorganized according to the unpredictable opportunities or disappointments that come with interdisciplinary research, than it would be possible in a preconceived institutionalized interdisciplinary structure. On the other hand, such an arrangement can also deprive a researcher from the necessary resources that can only be provided by a fullblown interdisciplinary infrastructure.

\section{References}

Andersen, Hanne, and Wagenknecht, Susann. 2013: "Epistemic dependence in interdisciplinary groups". Synthese 190(11), 1881-1898.

Hornbostel, Stefan. 2009: „Promotion im Umbruch - Bologna ante Portas“. In: M. Held, G. Kubon-Gilke, and R. Sturn (eds.): Jahrbuch Normative und institutionelle Grundfragen der Ökonomik, Band 8, Bildungsökonomie in der Wissensgesellschaft. Marburg: Metropolis Verlag, 213-240.

Hornbostel, Stefan, and Olbrecht, Meike. 2007: Peer Review in der DFG: die Fachkollegiate. iFQ-Working Paper, No. 2. Bonn.

Huutoniemi, Katri. 2010: "Evaluating Interdisciplinary Research". In: R. Frodeman (ed.): The Oxford Handbook of Interdisciplinarity. Oxford University Press, 309-320.

Kaiser, Marie I., Kronfeldner, Maria, and Meunier, Robert. 2014: "Interdisciplinarity in Philosophy of Science". Journal for General Philosophy of Science, 45(1), 59-70.

Kronfeldner, Maria, Neil Roughley, and Georg Toepfer. 2014: "Recent Work on Human Nature: Beyond Traditional Essences." Philosophy Compass 9 (9): 642-52.

Reydon, Thomas A.C., and Hoyningen-Huene, Paul. 2011: "Philosophie und ihr Verhältnis zu den Einzelwissenschaften.” In: Marcel van Ackeren, Theo Kobusch, and Jörn Müller, Warum noch Philosophie?: historische, systematische und gesellschaftliche Positionen. Walter de Gruyter, 127-145.

Sondermann, Michael, Simon, Dagmar, Scholz, Anne-Marie, and Hornbostel, Stefan. 2008: Die Exzellenzinitiative: Beobachtungen aus der Implementierungsphase. iFQ Working Paper, No. 5. Bonn.

Steel, Daniel. 2004: “Can a reductionist be a pluralist?” Biology and Philosophy, 19(1), 55-73. 